\title{
Optimal Location of the Facts Devices using the Sensitivity Approach for the Enhancement of ATC and Voltage Profile in Deregulated Power System
}

\author{
T. Sai Sudheer \\ JNTU Kakinada \\ QISCET
}

\author{
J. Srinivasa Rao \\ JNTU Ananthapur \\ QISCET
}

\author{
J. Amarnath \\ JNTU Hyderabad \\ E.E.E department
}

\begin{abstract}
The need for the enhancement of the Transfer Capability in a deregulated power system is very essential in the power market. Available Transfer capability (ATC), and Total Transfer capability (TTC), enhancement ensures to increase the Transfer capability in a power system. Improvement of the TTC and ATC depends upon the placement of the FACTS device; sensitivity approach is used to locate the optimal location to place FACTS device. However enhancement of ATC and TTC with voltage analysis is very essential, this helps us to estimate the security of the system which is very crucial when the performance of the system is the major criteria. Repeated power flow program is used to calculate the voltage constrained ATC and TTC. Transfer capability and voltage analysis proposed in this paper are simulated in the power world simulator software.
\end{abstract}

\section{Keywords}

Deregulated power system, TTC, ATC, TCSC, Total real power losses, voltage stability, PV \& V-Q curves.

\section{INTRODUCTION}

Power system is a very vast and complex entity. The study of power system and its components enabled the engineers to satisfy the growing need for the electrical power demand. Power system load growth is increasing at a faster pace compared to that of the transmission system capability. Basing on the load growth observed in the power system the need for the expansion of the transmission as well as other part of the power system is essential. However the expansion of the transmission system is quite a feat. This is because of the problems such as right of way, complete replacement of the working equipment for the expanded transmission system etc. Power flow through a conductor in a transmission system is limited by the voltage level, current flow, atmospheric conditions etc. The capital cost involved for replacing an already existing transmission network is quite huge. By placing a FACTS device in the existing transmission network

ATC of the transmission network in that area can be improved considerably.

Several methods have been suggested by many authors for the optimal placement of FACTS devices. D. Venu Madhava Chary and J. Amarnath. suggested the use of complex valued neural network approach in locating FACTS devices for the improvement of Transfer Capability [1]. Wu G., Yokoyama A., He J., Yu Y., suggested the allocation and control of FACTS devices for stability improvement [4]. The performance of the FACTS devices discussed in the references [2,3]. References [8,9] proposed the usage of the Continuation power flow approach. Available transfer capability definitions and determination is given in the reference [10]. Concepts and technology of FACTS devices is given by Hingorani N.G,Gyugyi [11].

As series compensation is most effective method to improve the power transfer in an existing transmission line this paper suggests the sensitivity approach for the optimal placement of FACTS devices for the improvement in ATC of the line. This paper also discusses the TTC and voltage analysis after the placement of FACTS devices. This approach is based on the calculation of the sensitivities of the individual transmission lines to find the line in which the device is to be placed for optimal performance of the power system.

Transfer capability is a very important criterion which is essential for the better understanding and better control of power system. For a secured power system the power transfers should not exceed certain fixed values called limits which act as threshold points of the system which help the system operate without violating the constraints existing in the system. It shows the ability of the system to transfer power from one area to the other. It also gives us the estimation regarding the existing capability of the system and the future needs for the expansion in the utilization of the transmission system. The main constraints which limit the transfer capability are given as:

\section{- Thermal constraints \\ - $\quad$ Voltage constraints and \\ - $\quad$ Stability constraints.}

Thermal related constraints may cause over heating of conductor thereby decreasing the life span of the conductor. The line sag also increases with temperature which may cause conductor to ground clearance violation and loss of mechanical strength.

Voltage related constraints cause the voltage dip or swell problems which may in turn cause insulation failure, interference with adjacent communication lines, inadequate operation and damage of equipment.

With the advancement of flexible ac transmission system (FACTS) devices power utilities all over the world are able to improve the transmission system security and provide strategic benefits for better utilization of the existing power system. The FACTS devices are based on the power electronic controllers. These devices are used to improve the performance of the transmission lines and also reduce the transmission losses and thus increasing the transmission 
system efficiency. FACTS devices also help in increasing the potential of the transmission lines by controlling the power flows in the system. FACTS devices are to be operated in a way so as to satisfy the requirements as much as possible by reducing the congestion in the transmission lines.

The concept of the FACTS devices was first proposed by Hingorani [12]. The power system can be operated in a more secured and flexible way with the help of FACTS devices.

\section{AVAILABLE TRANSFER CAPABILITY}

Available transfer capability (ATC) is a measure of the transfer capability remaining in the physical transmission network for further commercial activity over and above already committed uses. Mathematically, ATC is defined as the Total Transfer Capability (TTC) less the Transmission Reliability Margin (TRM), less the sum of existing transmission commitments (which includes retail customer service) and the Capacity Benefit Margin (CBM)

There are methods to calculate the transfer capability, which are given below.

\section{CONTINUATION POWER FLOW APPROACH}

Continuation power flow method is a comprehensive tool for tracing the steady state behavior of the power system due to parametric variation. The parameters which are varied include bus real and/or reactive loads, area real and /or reactive loads and real power generations at generator or P-V buses. Continuation methods are also known as curve tracing or path following which are used to trace solution curves for general non-linear algebraic equations with a parametric variation.

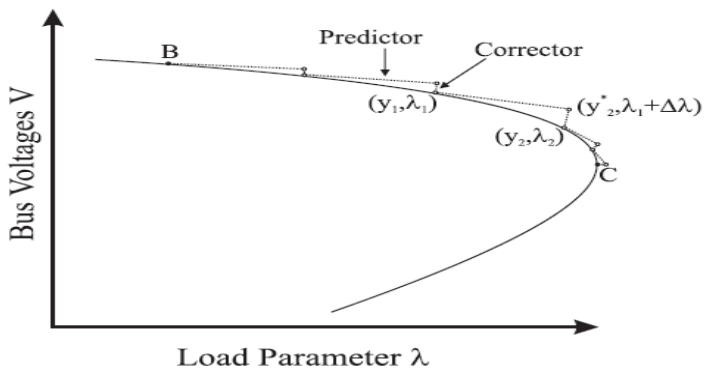

Figure-1. Predictor and corrector method of CP Flow

\section{OPTIMAL POWER FLOW APPROACH}

The application of Optimal Power Flow (OPF) in power system congestion management has been studied by some researchers, TTC calculation by OPF approach has been proposed since 1999. The basic concept of OPF approach is formulating the TTC calculation as an optimization problem, with equity constraints of power flow, inequality constraints from basic operation and equipment limits to more detailed approximation of transient stability security requirements. To determine the total transfer capability the objective is to maximize the power transfer between the two areas subjected to the conditions that there is no voltage or thermal or stability limit violations.

\section{REPEATED POWER FLOW APPROACH}

Repeated power flow approach starts from a base case, and repeatedly solves the power flow equations each time increasing the power transfer by a small increment until an operation limit is reached. The advantage of this approach is its simple implementation and the ease to take security constraints into consideration. In this dissertation, this method is adopted to solve TTC problem.

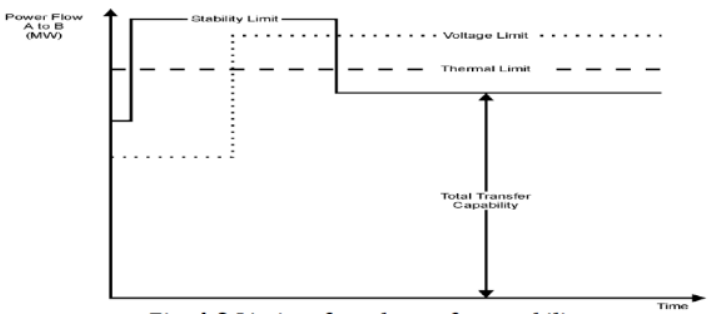

Figure-2. Limits of total transfer capability

VOLTAGE PROFILE ANALYSIS (PV AND QV CURVES)

Voltage profile analysis is carried out using the PV and QV or $\mathrm{V}-\mathrm{Q}$ curves. PV curves show us the relation between the Active power and the bus voltages in pu. Similarly QV curves show us the relation between the Reactive power and the bus voltages in $\mathrm{pu}$.

PV curves are useful for conceptual analysis of voltage stability and for study of radial systems. The method is also used for large interconnected network where $\mathrm{P}$ is the total load in an area and $\mathrm{V}$ is the voltage of a critical bus. P could be the power transferred over a transmission line voltage at several busses can be plotted. A disadvantage of the load flow solution for PV curve is that it is likely to diverge near the maximum power transfer point or the nose point of the PV curve.

V-Q curves plot voltage at a test or critical bus versus reactive power on the same bus. Since in a V-Q curve the power is to be kept fixed and it is required to obtain the reactive power for a set of scheduled voltage at the bus. This means we fix $\mathrm{P}$ and voltage magnitude at a representative bus and perform a load flow. Here we connect fictitious synchronous condenser at the bus and allow the bus to have any reactive power for a fixed $\mathrm{P}$ and $\mathrm{V}$.

\section{STATIC MODELLING OF TCSC}

Thyristor controlled capacitor (TCSC) is connected in series with the transmission lines. It is used to reduce the series line inductance by compensating with the capacitive reactance connected in series there by reducing the net series reactance of the transmission line. The transmission line model with a TCSC connected between the two busses $i$ and $j$ is shown in Figure-3. Equivalent pi model is used to represent the transmission line. TCSC can be considered as a static reactance of magnitude equivalent to $-j X$. The controllable reactance $X c$ is directly used as control variable to be implemented in power flow equation.

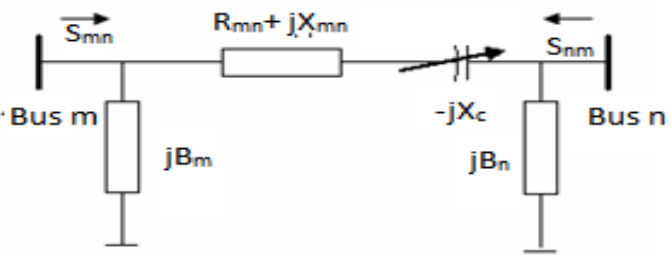

Figure-3. Transmission line model with TCSC. 
The following equations are used to model TCSC.

Let the voltages at bus $i$ and bus $j$ are represented by $V m \angle \delta \mathrm{m}$ and $V n \angle \delta$ n The complex power from bus $i$ to $j$ is

$\mathrm{S}_{\mathrm{mn}}^{*}=\mathrm{P}_{\mathrm{mn}}-\mathrm{Q}_{\mathrm{mn}}=\mathrm{V}_{\mathrm{m}}^{*} \mathrm{I}_{\mathrm{mn}}$

$=\mathrm{V}_{\mathrm{m}}^{*}\left[\left(\mathrm{~V}_{\mathrm{m}}-\mathrm{V}_{\mathrm{n}}\right) \mathrm{Y}_{\mathrm{mn}}+\mathrm{V}_{\mathrm{m}}\left(\mathrm{jB} \mathrm{B}_{\mathrm{mn}}\right)\right]$

$=\mathrm{v}^{*}{ }_{\mathrm{m}}\left[\left[\mathrm{G}_{\mathrm{mn}}+\mathrm{j}\left(\mathrm{B}_{\mathrm{mn}}+\mathrm{B}_{\mathrm{c}}\right)\right]-\mathrm{V}_{\mathrm{m}}^{*} \mathrm{~V}_{\mathrm{n}}\left(\mathrm{G}_{\mathrm{mn}}+\mathrm{j} B_{\mathrm{mn}}\right)\right]$

Where

$\mathrm{G}_{\mathrm{mn}}+\mathrm{j} \mathrm{B}_{\mathrm{mn}}=1 /\left(\mathrm{R}_{\mathrm{L}}+\mathrm{j} \mathrm{X}_{\mathrm{L}}-\mathrm{j} \mathrm{X}_{\mathrm{C}}\right)$

From the above equations the real and reactive power equations can be written as

$\mathrm{P}_{\mathrm{mn}}=\mathrm{V}_{\mathrm{m}}^{2} \mathrm{G}_{\mathrm{mn}}-\mathrm{V}_{\mathrm{m}} \mathrm{V}_{\mathrm{n}} \mathrm{G}_{\mathrm{mn}} \cos \left(\delta_{\mathrm{m}}-\delta_{\mathrm{n}}\right)$

$-\mathrm{V}_{\mathrm{m}} \mathrm{V}_{\mathrm{n}} \mathrm{B}_{\mathrm{mn}} \sin \left(\delta_{\mathrm{m}}-\delta_{\mathrm{n}}\right)$

$\mathrm{Q}_{\mathrm{mn}}=-\mathrm{V}_{\mathrm{m}}^{2}\left(\mathrm{~B}_{\mathrm{mn}}+\mathrm{B}_{\mathrm{c}}\right)-\mathrm{V}_{\mathrm{m}} \mathrm{V}_{\mathrm{n}} \mathrm{G}_{\mathrm{mn}} \sin \left(\delta_{\mathrm{m}}-\delta_{\mathrm{n}}\right)$

$+\mathrm{V}_{\mathrm{m}} \mathrm{V}_{\mathrm{n}} \mathrm{G}_{\mathrm{mn}} \cos \left(\delta_{\mathrm{m}}-\delta_{\mathrm{n}}\right)$

Similarly the real and reactive powers from bus $\mathrm{j}$ to $\mathrm{i}$ can also be represented replacing $V$ by $V$.

The real and reactive power losses in a line are represented by equations (7) and (8).

$\mathrm{P}_{\mathrm{L}}=\mathrm{P}_{\mathrm{mn}}+\mathrm{P}_{\mathrm{nm}}$

$\mathrm{Q}_{\mathrm{L}}=\mathrm{Q}_{\mathrm{mn}}+\mathrm{Q}_{\mathrm{nm}}$

\section{LOCATING THE FACTS DEVICES}

The objectives for device placement may be one of the following:

a) Reduction in the real power loss of a particular line

b) Reduction in the total system real power loss

c) Reduction in the total system reactive power loss

d) Maximum relief of congestion in the system

Basing on the requirement in the objectives the method is to be chosen. Trial and error method is most basic method and its complexity and time taken rises as the bus number increases. Sensitivity approach is just an alternative method to find the optimal location of the FACTS device.

\subsection{SENSITIVITY APPROACH}

Using the loss sensitivities the criteria for deciding device location might be stated as follows: 1 . TCSC must be placed in the line having the most positive loss sensitivity index. The procedure is shown in below flow chart.

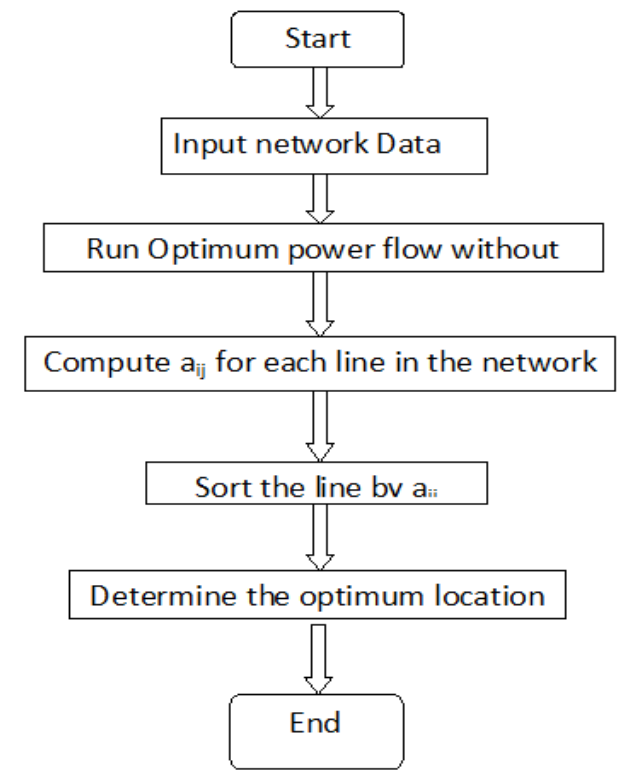

Figure-4. Flow chart for sensitivity approach.

The sensitivities of the lines are calculated using the formula

$\mathrm{a}_{\mathrm{mn}}=\left(\mathrm{V}_{\mathrm{m}}^{2}+\mathrm{V}_{\mathrm{n}}^{2}-2 \mathrm{~V}_{\mathrm{m}} \mathrm{V}_{\mathrm{n}} \cos \left(\delta_{\mathrm{m}}-\delta_{\mathrm{n}}\right)\right) *\left(\left(\mathrm{R}_{\mathrm{mn}}{ }^{2}-\mathrm{X}_{\mathrm{mn}}{ }^{2}\right) /\left(\mathrm{R}_{\mathrm{mn}}{ }^{2}+\mathrm{X}_{\mathrm{mn}}{ }^{2}\right)^{2}\right)$

By calculating the values of the $a_{m n}$ and tabulating these values we choose the line with most positive $a_{m n}$ value to place the TCSC.

\section{RESULTS AND DISCUSSION}

\section{5-BUS SYSTEM:}

The proposed method is applied to a modified IEEE 5-bus system. Modified IEEE 5-bus shown in Figure-5.

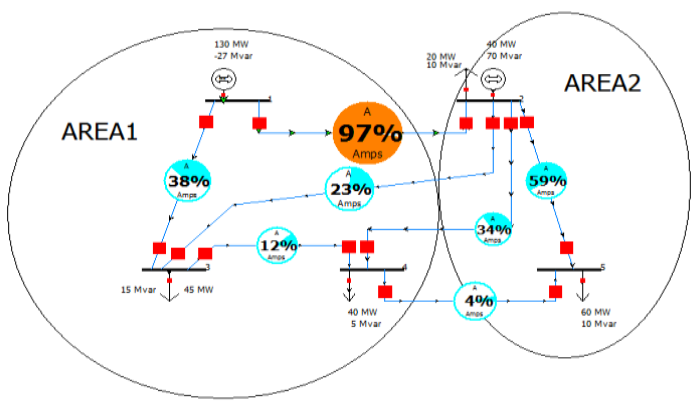

Figure-5. 5-bus system. 
Table-1. Sensitivity factors for 5-bus system.

\begin{tabular}{|c|c|c|c|}
\hline line no. & From bus & $\begin{array}{c}\text { To } \\
\text { bus }\end{array}$ & Sensitivity coefficient (aij). \\
\hline 1 & 1 & 2 & -0.70414 \\
\hline 2 & 1 & 3 & -0.13214 (most positive) \\
\hline 3 & 2 & 3 & -0.57429 \\
\hline 4 & 2 & 4 & -0.70022 \\
\hline 5 & 2 & 5 & -0.2559 \\
\hline 6 & 3 & 4 & -0.70850 \\
\hline 7 & 4 & 5 & -0.335486 \\
\hline
\end{tabular}

In the analysis we find the optimal placement of TCSC using sensitivity approach. In this method we need to calculate value of $\mathrm{a}_{\mathrm{ij}}$ for each and every branch of the 5-bus system. These values are tabulated and are shown above. Here TCSC is placed in the line 1-3.

Case 1 : area 1 to area 2 .

Case 2 : area 2 to area 1

Case 3 : area 1 to area 2 (with load changed)

Case 4 : area 2 to area 1 (with load changed)

Table-2 . ATC of 5-Bus system for different cases.

\begin{tabular}{|c|c|c|c|c|}
\hline Case & $\begin{array}{c}\text { Limitng } \\
\text { element }\end{array}$ & Base case & $20 \%$ TCSC & $80 \%$ TCSC \\
\hline CASE-1 & Line 1-2 & 8.43 & 13.75 & 36.86 \\
\hline CASE-2 & Area 1 & 130.43 & 130.4 & 131.46 \\
\hline CASE-3 & Line 1-2 & 0.57 & 6.23 & 30.94 \\
\hline CASE-4 & Area 1 & 139.09 & 139.12 & 140.23 \\
\hline
\end{tabular}

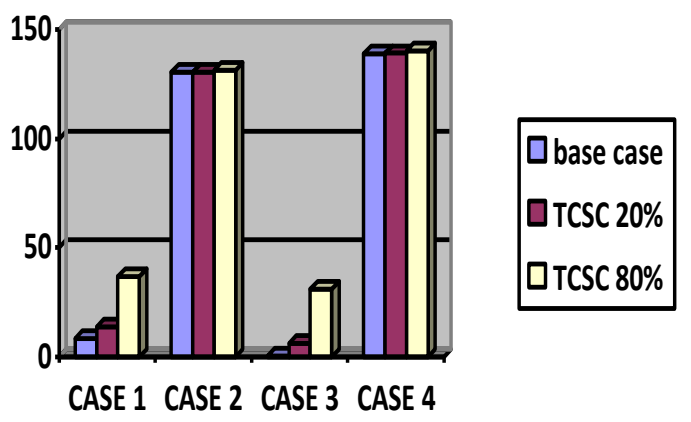

Figure 6. ATC for 5-bus system for different cases.

The effect of TCSC when placed in the optimal location in a modified IEEE 5- Bus system is demonstrated. It was shown that by placing a TCSC we can enhance the ATC of a power system by considerable amounts, here in base case the ATC for case- 1 is $8.43 \mathrm{MW}$ which was increased to $36.86 \mathrm{MW}$ for $80 \%$ TCSC. TTC

Case 1:Area 1 generation increasing to area 2 generation decreasing.

Case 2:Area 2 generation increasing to area 1 generation decreasing.
Table -3 TTC of 5- Bus system for different cases.

\begin{tabular}{|c|c|c|c|c|c|}
\hline Case & $\begin{array}{c}\text { Limiting } \\
\text { element }\end{array}$ & $\begin{array}{c}\text { Without } \\
\text { compensatio } \\
\mathrm{n}\end{array}$ & $\begin{array}{c}20 \% \\
\text { TCSC }\end{array}$ & $\begin{array}{c}40 \% \\
\text { TCSC }\end{array}$ & $\begin{array}{c}80 \% \\
\text { TCSC }\end{array}$ \\
\hline A 1- A2 & $1-2$ & 53.46 & 56.46 & 60.39 & 83.46 \\
\hline A 2- A1 & $1-3$ & 161.54 & $\begin{array}{c}158.4 \\
1\end{array}$ & $\begin{array}{c}154.2 \\
9\end{array}$ & $\begin{array}{c}148.6 \\
9\end{array}$ \\
\hline
\end{tabular}

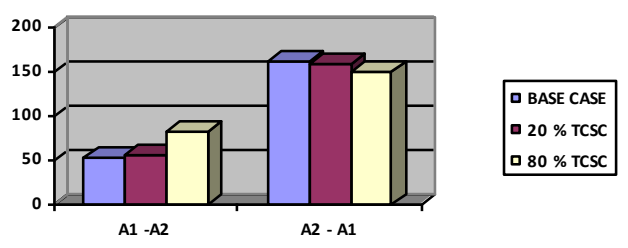

Figure 7. TTC of 5-bus system for different cases.

The TTC of modified IEEE-5 Bus system is improved by placing the TCSC in the system. Initial value of the TTC in the base case was observed to be $53.46 \mathrm{MW}$ which was improvised to $83.46 \mathrm{MW}$ after placing TCSC for $80 \%$ compensation.

\section{VOLTAGE PROFILE ANALYSIS}

\section{PV CURVES}

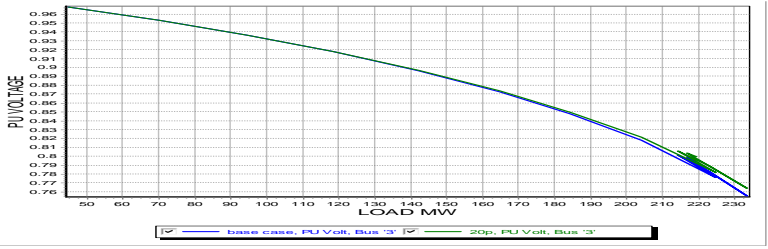

Figure 8. PV curve at bus-3 with $20 \%$ comp.

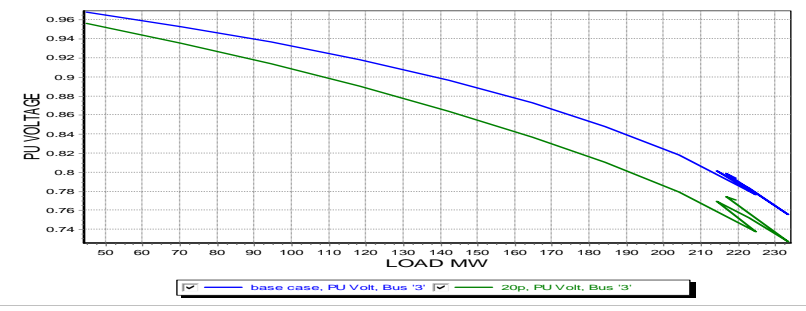

Figure 9. PV curve at bus-3 with $80 \%$ comp.

From the above pv-curves it is noticeable that the voltage stability of the load busses is improved by a satisfactory range by placing the FACTS device in the optimal location suggested by using the sensitivity approach.

\section{QV CURVES}
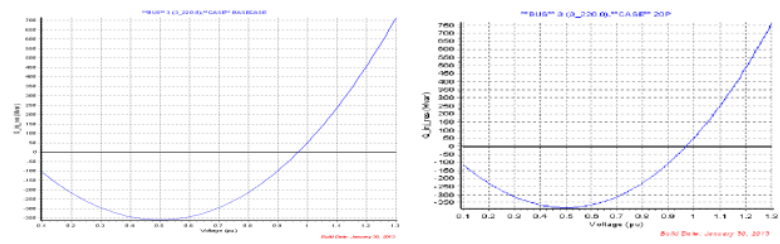

Figure 10. QV curve at bus-3 with $20 \%$ comp. 

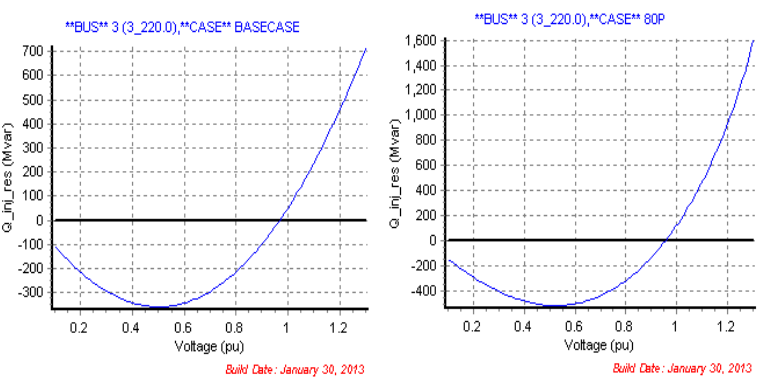

Figure 11. QV curve at bus-3 with $80 \%$ comp.

By observing the QV curves how much reactive power reserves available in the system for various voltage levels and placing the series device in the system which does not effect on the reactive power control.

\section{9- BUS SYSTEM}

The proposed method is applied to a modified IEEE 9-bus system. Modified IEEE 9-bus shown in Figure-12.

\section{Figure 12. 9-bus system.}

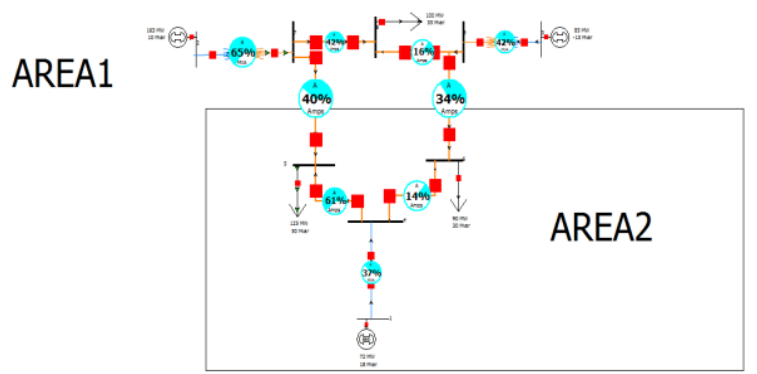

TABLE-4. Sensitivity factors for 9-bus system.

\begin{tabular}{|c|c|c|c|}
\hline Line no. & From & To & sensitivity coefficient $\left(\mathrm{a}_{\mathrm{ij}}\right)$ \\
\hline 1 & 1 & 4 & -0.552 \\
\hline 2 & 2 & 7 & -2.668142 \\
\hline 3 & 3 & 9 & -0.7045132 \\
\hline 4 & 4 & 5 & -0.306025 \\
\hline 5 & 4 & 6 & -0.054231 \\
\hline 6 & 7 & 5 & -0.57533 \\
\hline 7 & 9 & 6 & -0.45946 \\
\hline 8 & 7 & 8 & -0.692995 \\
\hline 9 & 9 & 8 & -0.000253 \\
\hline
\end{tabular}

Line 9-8 is the line with most positive sensitive factor, so TCSC is to be placed in the line 9-8 in the above 9-bus system.

Case 1 : area 1 to area 2.

Case 2 : area 2 to area 1

Case 3 : area 1 to area 2 (with load changed)

Case $4:$ area 2 to area 1 (with load changed)
Table -5. ATC for 9-Bus system for different cases.

\begin{tabular}{|c|c|c|c|c|}
\hline case & $\begin{array}{c}\text { Limitng } \\
\text { element }\end{array}$ & Base case & $\begin{array}{c}20 \% \\
\text { Compensation } \\
\text { (TCSC) }\end{array}$ & $\begin{array}{c}80 \% \\
\text { Compensation } \\
\text { (TCSC) }\end{array}$ \\
\hline CASE 1 & Area 2 & 71.95 & 71.95 & 72 \\
\hline CASE 2 & Line 5-4 & 107.87 & 109.42 & 115.35 \\
\hline CASE 3 & Area 2 & 132.67 & 132.69 & 132.83 \\
\hline CASE 4 & Line 5-4 & 38.69 & 41.35 & 51.21 \\
\hline
\end{tabular}

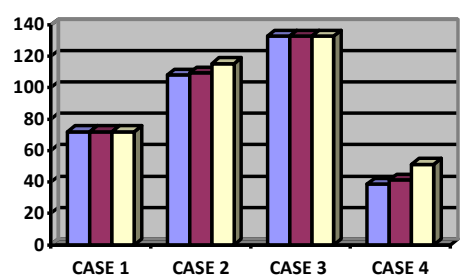

Q BASE CASE

$\square \mathbf{2 0 \%}$ TCSC

$\square 80 \%$ TCSC

\section{Figure 13. ATC for 9-bus system for different cases.}

The effect of TCSC placed in the optimal location in a modified IEEE 9- Bus system is demonstrated above. It is evident that by placing a TCSC we can enhance the ATC of a power system by considerable amount, here in base case the ATC for case-2 is $107.87 \mathrm{MW}$ which is increased to $115.35 \mathrm{MW}$ for $80 \%$ TCSC. TTC

Table-6. TTC of 9 Bus system for different cases.

\begin{tabular}{|c|c|c|c|c|c|}
\hline case & $\begin{array}{c}\text { Limit } \\
\text { ing } \\
\text { eleme } \\
\text { nt }\end{array}$ & $\begin{array}{c}\text { Without } \\
\text { compens } \\
\text { ation }\end{array}$ & $\begin{array}{c}20 \% \\
\text { compens } \\
\text { ation } \\
\text { (TCSC) }\end{array}$ & $\begin{array}{c}40 \% \\
\text { compensat } \\
\text { ion } \\
\text { (TCSC) }\end{array}$ & $\begin{array}{c}80 \% \\
\text { compens } \\
\text { ation } \\
\text { (TCSC) }\end{array}$ \\
\hline $\begin{array}{c}\text { A 1- } \\
\text { A2 }\end{array}$ & $2-7$ & 321.62 & 322.12 & 323.36 & 324.5 \\
\hline $\begin{array}{c}\text { A 2- } \\
\text { A1 }\end{array}$ & $5-4$ & 41.38 & 36.11 & 34.21 & 30.09 \\
\hline
\end{tabular}

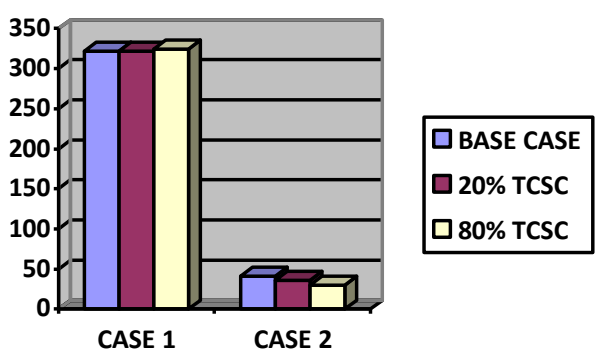

Figure 14. TTC of 9-Bus system.

The TTC of modified IEEE-9 Bus system is improved by placing the TCSC in the power system. Initial value of the TTC in the base case was observed to be $321.62 \mathrm{MW}$ which was improvised to $324.5 \mathrm{MW}$ after placing TCSC for $80 \%$ compensation. 


\section{VOLTAGE PROFILE}

\section{PV CURVES}

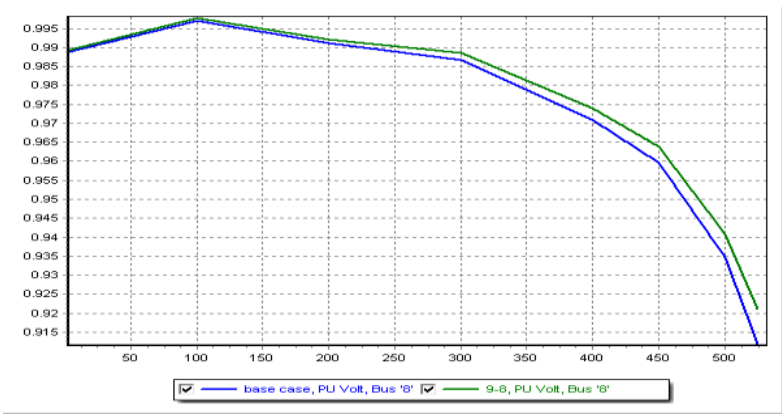

Figure 15. PV curve at bus-8 with $20 \%$ TCSC

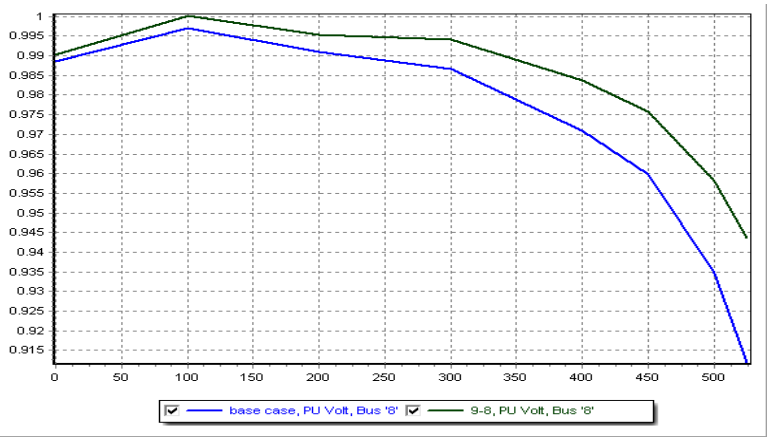

Figure 16. PV curve at bus-8 with $80 \%$ TCSC

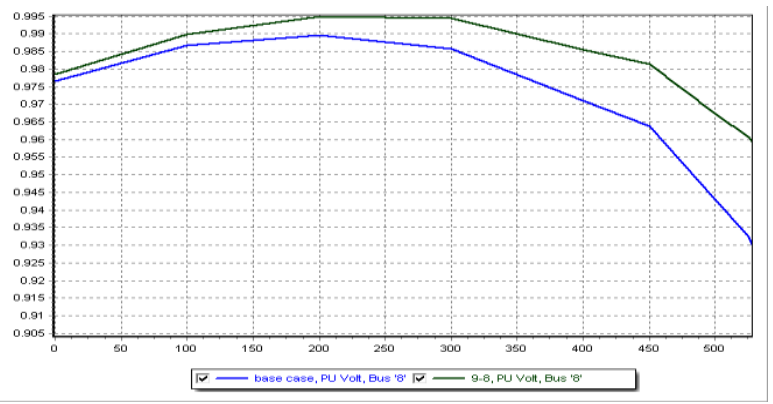

Figure 17. PV curve at bus-8 with $80 \%$ TCSC with change in load

PV plots are shown for few load busses existing in the system. Change of the voltage stability can be observed from the above pv-plots and the voltage stability margins are increased with the increase of the compensation level of the TCSC.

\section{QV CURVES}
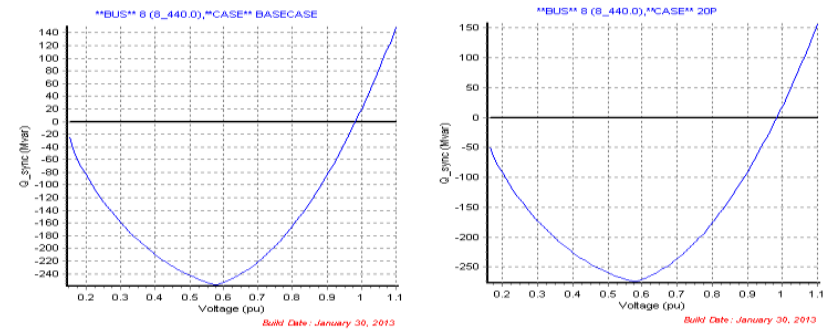

Figure 18. PV curve at bus-8 with $20 \%$ TCSC
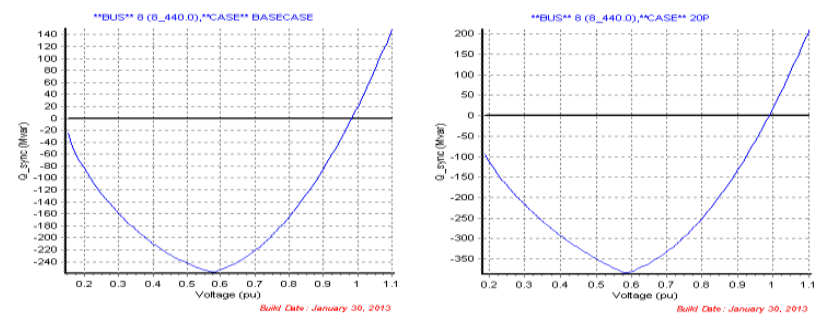

Figure 19. PV curve at bus-8 with $80 \%$ TCSC.
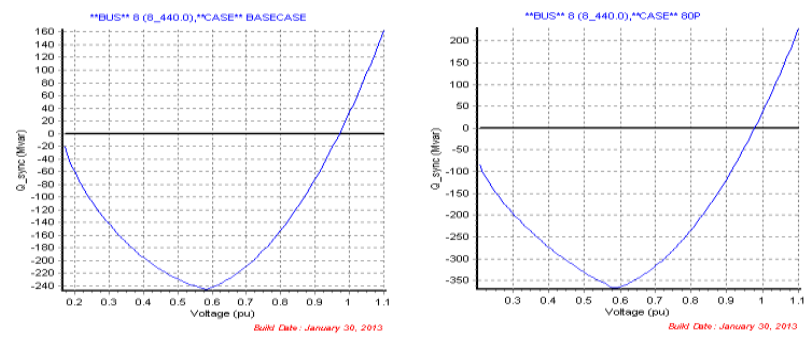

Figure 20. PV curve at bus-8 with $80 \%$ TCSC with change in load

By observing the QV curves how much reactive power reserves available in the system for various voltage levels and placing the series device in the system which does not effect on the reactive power control.

\section{CONCLUSION}

The results produced in this paper show the enhancement of TTC and ATC in 5-Bus and 9-Bus systems and voltage profiles for the same. PV and QV curves show the security level of the system for the growth of load at load busses. Improvement in the TTC, ATC and voltage profile can be observed from the results and discussion section of this paper. The change observed is a proof that this approach is suitable for the enhancement of ATC and TTC.

\section{REFERENCES}

[1] D. Venu madhava chary, J. Amarnath.2010 "complex neural network approach to optimal location of FACTS devices for Transfer Capability enhancement",ARPN Journal of Engineering and applied sciences VOL-5, No. 1, January 2010.

[2] Galiana G.D. 1996. Assessment and control of the impact of FACTS devices on power system performance. IEEE Transactions on Power System. 11(4): 1931-1936.

[3] Larsen E., Millers N., Nilsson S., Lindgren S. 1992. Benefits of GTO-Based compensation systems for electric utility applications. IEEE Transactions on Power Delivery. 7(4): 2056-2064.

[4] Wu G., Yokoyama A., He J., Yu Y. 1998. Allocationand control of FACTS devices for steady state stability enhancement of large scale power system. IEEE International Conference on Power System Technology. 1: $357-361$.

[5] Preedavinchit P., Srivastava S.C. 1998. Optimal reactive power dispatch considering FACTS devices.Electric Power Systems Research. 46(3): 251-257. 
[6] Momoh J.A., Zhu J.Z. 1998. A new approach tooptimal power flow with phase shifter. IEEEInternational Conference on Systems. 5: 4794-4799.

[7] De Oliveira E.J., Lima W.M. 1999. Allocation of FACTS devices in a competitive environment. $13^{\text {th }}$ PSCC. pp. 1184-1190.

[8] V. Ajjarapu and C. Chrity. 1992. The Continuation Power Flow: A tool for steady state Voltage stability Analysis. IEEE Transactions on power systems. 7(1): 416-423.

[9] H.D. Chinag, A.J. Flueck, K.S. Shah and N. Balu. 1995. CP FLOW: A practical Tool for Tracing Power system Steady state stationary behaviour due to the load and generation variations. IEEE Transactions onpower systems. 10(2): 623-634.

[10] 1996. Transmission Transfer Capability Task Force (NERC). Available transfer capability definitions and determination.

[11] Hingorani N.G, Gyugyi L. 2000. Understanding FACTS: Concepts and Technology of Flexible AC Transmission Systems. Institute of Electrical and Electronic Engineers Press, New York.

[12] B. Widrow, J. Mc Cool and M. Ball. 1975. The Complex LMS algorithm. Proc. of the IEEE. April. 